\title{
A cross-sectional study of student empathy across four medical educations in Denmark - associations between empathy level and age, sex, specialty preferences and motivation
}

\section{Elisabeth Assing Hvidt ( $\square$ ehvidt@health.sdu.dk )}

Research Unit of General Practice, Department of Public Health, University of Southern Denmark Jens Søndergaard

Research Unit of General Practice, Department of Public Health, University of Southern Denmark

Sonja Wehberg

Research Unit of General Practice, Department of Public Health, University of Southern Denmark Niels Christian Hvidt

Research Unit of General Practice, Department of Public Health, University of Southern Denmark Christina Maar Andersen

Department for Psychology, University of Southern Denmark

\section{Research Article}

Keywords: Empathy level, cross-sectional study, Jefferson Empathy Scale (Student Version), Denmark, medical education, specialty preferences, motivations

Posted Date: March 3rd, 2022

DOI: https://doi.org/10.21203/rs.3.rs-1319897/v1

License: (c) (1) This work is licensed under a Creative Commons Attribution 4.0 International License.

Read Full License 


\section{Abstract}

Background: Professional empathy has been associated with a range of positive patient- and clinician outcomes and is therefore considered important to develop for future physicians. Measuring changes in empathy scores among medical students by using the Jefferson Scale of Empathy (Student version) (JSE-S) has led to mixed results. So far, no investigation of Danish medical students' empathy development has been conducted. The aim of this study was therefore to examine the associations between empathy scores among Danish medical students and university, year of curriculum, age, sex, cohabitation, and parental status, specialty preferences and motivations for choosing the medical education.

Methods: This was a cross-sectional questionnaire study. All medical students in Denmark in their first, third and sixth year $(\mathrm{N}=4,178)$ were invited to participate in the study in October 2020. The associations between JSE-S sum score and the above explanatory factors were analysed by uni- and multivariable linear regression models.

Results: The JSE-S was completed by 672 medical students. The overall mean score was 112.7. There were no statistically significant differences in empathy between universities, first, third- and sixth-year medical students, age groups or parental status. Female students and students living with a spouse or partner scored higher on JSE-S than male students or students living alone, and the sex difference remained statistically significant in the multivariable regression. In both the univariable and multivariable setting, preference for future medical specialty was statistically significant, with a decrease in scores for students choosing surgery-specialties. Motivational factors were not statistically significantly associated with empathy, although there was a slight upwards trend for one of the motivational categories, named "personal experiences".

Conclusions: Overall, our results, showing rather stable empathy scores across years of curriculum of medical students in Denmark, add to the mixed picture of empathy development among medical students. Our findings are consistent with positive associations found in international studies between empathy scores and higher age, female sex, human-oriented specialty preferences and altruistic motivations for choosing to enroll. Although specialty preferences are changing during a medical education, they may be used meaningfully as predictors of individual student empathy levels.

\section{Background}

Professional empathy is considered an important attribute to have and further develop for students in the medical education (1). Defined in the medical literature as the ability to understand a patient's suffering and concerns combined with an ability to communicate this understanding and an intention to help (24), professional empathy has been associated with a number of beneficial patient and physician outcomes: more accurate diagnosis and treatment, increased patient satisfaction and compliance $(3,5-$ 8), lower incidence of complaints and lawsuits, and lower levels of burnout and stress among physicians 
$(2,9,10)$. Moreover, high scores on professional empathy among medical students are associated with increased satisfaction with their education, lower levels of stress and burn-out, higher ratings of overall clinical competences given by medical school faculty, better interpersonal skills assessed by patients and greater teamwork skills $(2,11-13)$.

Much attention has been dedicated across countries and cultures to investigate the development in empathy among medical students, relying largely upon the Jefferson Scale of Empathy (Student version) (JSE-S), a self-report scale developed specifically to measure professional empathy in respect to patient care, reflecting primarily the cognitive (as opposed to the emotional) dimension of empathy (1).

The vast body of literature on student empathy development from different parts of the world was recently reviewed by Andersen et al. (14), who found that results from most cross-sectional studies investigating empathy across year of medical curriculum show a decrease in empathy level, although stability and increase in empathy levels are also reported in some studies. These mixed results are possibly related to study limitations (differences between cohorts, lacking details of respondents) and differences in study designs (single-institutional, lack of control groups, etc.) (9). In a more general sense, empathy varies in different cultures (15), and so the premise that empathy is comparable across medical educational cultures can be problematized. Taking these considerations to a side, results from studies in disparate cultural settings investigating associations between empathy scores and variables such as age, sex, and specialty preferences have largely found positive associations between empathy scores and higher age in students, female sex as well as student preferences for people-oriented specialties (versus technology and procedure-oriented specialties that deal more with techniques and instruments) $(14,16)$. Lastly, studies have consistently found interior motivational factors for studying medicine, e.g., a desire to care for patients, alleviate distress and save lives, to be positively associated with empathy in contrast to external motivational factors such as prestige, status, and future earning potential $(17,18)$.

Research investigating the influence of private life conditions - having children or not - on empathy is scarce. Since empathy constitutes an important psychosocial factor in parent-child-, and romantic relationships as well as human interaction in general (19), these social details of respondents are also important to take into consideration when investigating student empathy scores.

No investigation of Danish medical students' empathy development and associations to the abovementioned variables has yet been conducted. The aim of this study was to examine the associations between empathy scores as measured by JSE-S and students' university, year of curriculum, age, sex, cohabitation, parental status, specialty preferences and motivations. In the light of the afore-mentioned studies, the following hypotheses are investigated:

1. There are no significant differences in empathy scores across the four universities in Denmark since differences in culture and curriculum are expected to be small within the study sample.

2. Students in lower year of curriculum, i.e., 1st year, will have a higher level of empathy than students of higher years of curriculum, i.e., 3rd and 6th year.

3. Older and female students score higher on empathy than their younger and male counterparts 
4. Students who have children and who live with others (i.e., with a partner and/or friends) score higher in empathy than those without children and/or living alone.

5. Students preferring people-oriented specialties will score higher than those preferring technology and procedure-oriented specialties.

6. Students who choose to study medicine due to interior, prosocial or altruistic motivations (helping other people or society) score higher on empathy compared to students motivated by prestige, status, or monetary gain.

\section{Methods/design}

The study was designed as a national, cross-sectional questionnaire study targeting first, third- and sixthyear medical students in Denmark in October 2020.

\section{Study settings and samples}

First, third- and sixth year medical students from all four medical schools in Denmark (University of Copenhagen, Aarhus University, University of Southern Denmark and Aalborg University) were included in the study. In terms of length (six years) and content of curriculum the four medical schools in Denmark are similar. The curricula in the medical schools can be characterized as "traditional", meaning that it is divided into a preclinical phase predominated by transmission of theoretical input (bachelor level) and a clinical phase (graduate level) in which students see patients in one- to three-weeks internships. Thus, the students have limited clinical exposure during the first three years (bachelor). While the curriculum content in regard to medical humanities and empathy-enhancing subjects differ across universities (e.g., at some of the universities early contact with patients/citizens is included, at other universities literary courses like "narrative medicine" or medical ethics), teaching in communication (theory) and communication skills training (practice) through simulation (actors playing the role of patients) is included throughout the medical educations, covering approximately the same amount of European Credit Transfer System (ECTS) at each university.

In Denmark, the publicly funded universities offer tuition-free medical education thus reducing the influence of socioeconomic factors on medical students' choice of education. In addition, the Danish State offer financial aid to every Dane over the age of 18 who choose to educate him-/herself further regardless of socioeconomic standing. Admission to the medical education is allocated in two quotas: quota 1 admissions are allocated according to academic measures (college grades) whereas emphasis in quota 2 admissions is also placed on personal characteristics of applicants (including motivation, prior work experiences and social skills).

\section{Data collection}

Data was collected from the 15th of October to the 31st of December 2020 through an online questionnaire, set up in the electronic survey system SurveyXact by Rambøll (20). 
Students were informed about the study by receiving an information letter (the project was presented to students under the title: "Students' relations, values and mental health - what are the associations?". In the information letter it was clarified how the data of the student was used (in accordance with the General Data Protection Regulation (GDPR)) and the contact information on the principal investigators (XXX) was provided together with the contact information of the data protection officers of the faculty.

\section{Ethics}

Complying with European data protection rules, the University of Southern Denmark approved the data processing activities regarding this project, including permission to extract the students' civil registration number (CPR) and other relevant background information such as year, study start, grades, country origin, dropout, etc. from the faculties' enrolment lists, and registered the project under [Journal no. 10.181]. The study was furthermore approved by the research ethics committee of University of Southern Denmark (REC) [Journal no. 20/5351].

\section{The questionnaire}

In the questionnaire, students filled out the JSE-S (2) which in this study was used as a measure of professional (cognitive) empathy. It is a 20 -item scale developed to specifically measure medical students' personal orientation toward empathy in respect to patient care. For each item, the students' response is measured on a 7-point Likert scale (1-7). Reversely coded items were: 1, 3, 6, 7, 8, 11, 12, 14, 18,19 . A total sum score was calculated as the sum of scores of the directly worded items plus the reverse score of the negatively worded items. If one or two items had missing values, then these were replaced by the mean score of other items.

JSE-S has been extensively validated internationally. The JSE-S total score ranges from 20 to 140, with higher values indicating a higher degree of empathy. In past studies, total scores among medical students have ranged from 115 to 123.1 and standard deviations ranged from 9.9 to 14.1 (1). Before including the JSE-S in the questionnaire, it was translated into Danish according to the WHO's guidelines (21) and cognitive interviews were conducted by XXX and XXX with ten Danish medical students (22).

In the questionnaire, students also specified university, age, sex (categorized as 18-24 and 25+), whether they have children or not, and co-habitation status (whether living alone, with spouse/partner or with others), preferences for various specialities (see details below), and motivations behind choosing medicine (open-ended question, see details below). An overview of the other scales included in the questionnaire can be found in Assing Hvidt et al. (23)

To gather information regarding specialty preferences, students were asked to choose one specialty from a drop-down menu of all available medical specialties in Denmark (see list of medical specialities, appendix Table S1). To gather information regarding student motivation for choosing to enrol in the medical education, students were asked the following open question in the questionnaire: "What is your motivation for choosing the medical education?", stimulating reflections rather than predefined answer categories. 
XXX and XXX coded the given motivations into ten preliminary codes (see Table 2). The following four overall categorizations were subsequently developed: 1) Interest in the human body, indicating that the biological and physiological aspects of medicine motivate the choice to enrol 2) Interest in helping others/society, indicating that altruistic and communicative interests motivate the choice to enrol 3) Money, prestige and status, indicating that the prospect of future monetary gains, job security and societal status connected to the job motivate the choice to enrol and lastly 4) Personal experiences, indicating that prior good or bad experiences with illness (either through self or others), and a desire to optimize care, motivate the educational choice.

\section{Outcomes, explanatory factors and statistical analysis}

The outcome was self-reported empathy sum scores as measured with JSE-S within the cross-sectional sample of medical students. Explanatory factors were: university, age, sex, co-habitation, parental status, and specialty preferences and motivations behind choice of study.

Data analysis were both uni- and multivariable linear regression models for the outcome measure JSE-S. Throughout the analyses, a $p$-value below 0.05 was considered statistically significant. In addition, we compared responders to target group with respect to university, educational year, age and sex by a Chisquared test, excluding potential missing observations.

\section{Results}

\section{Participant characteristics}

Table 1 includes both an analysis of response rates and presents baseline characteristics of completers. A total of 4,178 medical students received an invitation to participate in the study of which 672 completed the questionnaire completely (16.1\%), 215 only partially and 3,291 did not respond.

Response rates differed across universities and between sexes ( $p$-values $<0.001$ ) (Table 1 ), while there were no statistically significant differences in response rates according to age or educational years. Across universities, response rates ranged from $10.6 \%$ in Copenhagen to $25.3 \%$ at the University of Southern Denmark. Female students were more inclined to respond than male students (18.3 vs. $11.7 \%$ ).

Looking at the distribution of characteristics in our analysis sample, participants were most often from the University of Southern Denmark (34.4\%) followed by Aarhus University (31.7\%), University of Copenhagen (24.4\%) and Aalborg University (9.5\%). Furthermore, participants were mostly female (75.4\%), under the age of 25 years (64.6\%) and first year students (41.7\%) (Table 1). The participants were mostly co-habitants (73.6\%) (living with others or spouse/partner versus living alone) and had no children (95.2\%). The most frequently stated specialty preferences were family medicine $(16.5 \%)$, pediatrics (9.5\%) and gynaecology and obstetrics (7.7\%).

\section{Associations between empathy and explanatory factors}


Table 3 depicts the students' score on JSE-S, showing the range of scores $=51-139$, mean $(S D)=112.7$ (10.8), interquartile range $=107-120$, median $=113$. The corresponding univariable regression results (Table 4) showed no statistically significant differences in empathy between universities, first, third- and sixth-year medical students, age groups or parental status. Female students scored $3.7(1.8 ; 5.5)$, $p$-value $<0.001$ points higher on JSE-S than male students, and this difference remained statistically significant in the multivariable regression $(2.5(0.6 ; 4.5), p$-value $<0.0115$. Further, compared to students that live alone, those who live with a spouse or partner scored $2.8(0.7 ; 4.9), p$-value $=0.0081$ points higher on empathy. The same trend was observed in the multivariable model, though the difference was no longer statistically significant. In both the univariable and multivariable setting, preference for future medical specialty was statistically significant with an overall $p$-value $<0.001$. In the multivariable model, with the specialty general practice as reference, students choosing psychiatry as specialty preference scored 5.4 $(0,6 ; 10.2), p$-value $=0.0268$ higher, whereas a decrease in scores was found for those choosing surgery $6.3(-10.0 ;-2.7), p$-value $<0.001$, neurosurgery $-7.4(-13.3 ;-1.5), p$-value $=0.0142$ and cardiothoracic surgery $-11.3(-18.5 ;-4.1), p$-value $=0.0022$, see Table 4 . Concerning the different motivational aspects, there were no statistically significant differences in the multivariable model except for "no motivation stated", which was associated with a decrease in empathy of $-4.1(-7.6 ;-0.5), p$-value $=0.0267$. The estimated coefficients were around zero for "interest in human body" (biology), "prestige and helping others/society". The motivation of "personal experiences" was associated with a slightly larger empathy score of $2.1(-0.5 ; 4.8)$, which was comparable to the effect of living status, though both were not statistically significantly different from zero.

\section{Participants' motivation}

Table 2 and Fig. 1 depict student motivations. Among all the students the motivations most often given (students could indicate as many motivations as they would like) were interest in the human body $(61.3 \%)$ and interest in helping others/society (61.2\%). When comparing motivations indicated by students at different years of curriculum, and among those still enrolled, the motivation to help others/society increased with higher educational year ((1st (56.4\%), 3rd (63.7\%) and 6th 65.6\%)) whereas the motivation personal experience decreased with higher year of curriculum (1st (19.3\%), 3rd (15.1\%) and 6th $(7.8 \%)$ ). More male students gave prestige as motivation for choosing to study medicine than did female students (17.6\% vs $12.0 \%$ ) whereas more female students cited personal experiences as motivation compared to male students ( $16.8 \%$ vs $9.1 \%)$.

\section{Discussion}

One of our hypotheses: that we would find no significant differences in empathy across universities in Denmark has been confirmed by our study results showing relatively high and stable empathy scores across universities. The results showing empathy scores to be stable across educational years are consistent with results found in other studies (24-27). Explanations for why empathy scores surprisingly did not decrease from first to sixth-year medical students (as hypothesized and found in prior evidence, see (14)) might be that clinically-situated empathy has been highlighted in recent years as an integral 
part of medical professionalism $(1,28,29)$, and thus formally as a "need to have" among medical students. This has led universities to include various programmes in the medical curriculum intended to foster empathy, such as reflective writing, literature courses, theatre workshops, communication skills training, etc. (30). Although several methodological limitations exist in studies evaluating the impact of these interventions on students' empathy, research suggests that focused educational interventions may be successful at fostering and maintaining empathy in medical students (31). Having said this, it must be noted that with the present study's cross-sectional design, one cannot know whether decreasing and/or increasing empathy scores might in fact have led to dropouts, meaning that the results of this study only reflect the development in empathy among those students who have chosen to stay enrolled up until the last year of curriculum.

In concert with many other studies recently reviewed in Andersen et al. (14), and supporting our hypothesis, we found that female medical students scored higher on empathy compared to male medical students. One explanation for this can be found in evolutionary psychology where empathy is viewed as a skill that women have developed due to their evolutionary primary role as caretakers of children, the elderly and sick people whereas men have developed skills related to hunting and defending the tribe (32). This view is also supported by the fact that most professional caretaker positions are occupied by women (33). Also, as pointed out by some authors, empathic behavior is expected of women by society a social and cultural construction of female personality traits, including conscientiousness, openness and agreeableness - a social desirability that we might see reflected in female respondents' self-reporting empathy scores (34).

\section{Specialties and motivations}

The findings did support the hypothesis that those students preferring human-oriented specialties would score higher on the empathy scale than those choosing technology-oriented specialties. This hypothesis seemed logical since technology-oriented specialties have been characterized as involving a low degree of relational contact and a low level of interpersonal continuity (35). This suggests that students answer consistently between specialty preferences and empathy orientations (presented in the JSE-S) which might mean that asking students about their specialty preferences at different time points (to capture possible changes of preferences) has a predictive validity, possibly higher than the one of a self-report empathy questionnaire such as JSE-S.

In relation to the specialties psychiatry and general practice, normally positioned in the high end of people-oriented specialties (36), we also found that students indicating psychiatry as a specialty preference scored higher on empathy than those students choosing general practice, although scores in both groups were high. The difference in empathy scores between the two groups of students might be attributed to the fact that psychiatry as specialty involves contact with patients whose severe mental disorders and social, existential, and spiritual life challenges require a high level of empathy. A specialty where treating people who are mentally and socially challenged might attract people with general high levels of moral and social indignation and compassion towards those who are stigmatized and live at the 
margins of society. General practice as specialty involves contact with a large proportion of healthy people coming to see the doctors about common, minor and/or self-limiting, medical conditions. Treating a relatively high number of people with chronic conditions, general practitioners often develop an ongoing relationship with their patients, providing continuity of care. Finally, the findings did support the hypothesis that students who choose to study medicine due to prosocial or altruistic motivations (helping other people or society) score higher on empathy compared to students motivated by prestige, status, or monetary gain. Enhancing altruistic motivations among students thus seems to be a relevant method to foster clinical empathy. Supporting this view, neurobiological studies show that motivations modulate empathy at the neural level (37). For example, having a desire to help other people who are in need and alleviate their suffering makes people especially motivated to empathize, which increases empathyrelated brain activity. Conversely, the desire for prestige, status and monetary gain makes people empathy avoidant, since showing empathy might be considered time consuming and non-rewarding, and hence decrease empathy-related brain activity $(37,38)$.

Moreover, we found that among those students still enrolled motivations among the students who were motivated by a wish to help others seemed to increase with year of curriculum. Although this observed tendency needs to be confirmed through longitudinal data, it can be explained by an increase in clinical experiences and patient contact over the years of curriculum that might lead to experiences of making a difference and causing positive changes via one's work competences. Observing the effect of one's work, whether on a biomedical or psycho-social level, might increase one's altruistic motivation.

The percentage of students (based on those remaining) expressing the motivations grouped under the category "personal experience" was also found to decrease. This category, indicating a desire to optimize care, might have been dominant behind the choice to enroll but might have diminished as other educational input and experiences are received. The decrease in motivations grouped under the category "personal experience" might also be caused by feelings of disillusion and/or realizing that the system is too powerful to be changed.

Interestingly, in relation to both specialty preferences and motivations, we found that there were no significant differences with respect to motivation in the multivariable regression model but considerable effects with respect to specialty preferences. This might suggest that specialty preferences (which are purely a wish at a certain time point) has a stronger link to (latent) empathy level than their current (retrospective) motivation.

\section{Strengths and limitations}

In our survey study, we invited the total population of all first, third- and sixth-year medical students in Denmark instead of a sample. As is always the case with surveys, the self-selected participants might have been particularly interested in the subject at hand, possibly also displaying a relatively higher level of empathy than those who did not contribute. A further limitation of this study is the relatively low response rate of $16 \%$. Low response rates in student surveys in higher education, in particular in connection with student evaluations of teaching, are however a well-known issue (39). Added to this, 
students might have felt a digital survey fatigue since a general trend during the Covid-19 pandemic was that students felt over-surveyed (40). To increase the response rate for this project, we had planned to visit students at the four universities during key lectures and request from teachers to use a couple of minutes to present the project. This was however made impossible by the Covid-19 pandemic and lockdown periods where all university teaching was diverted to online teaching. We did, however, advertise the project on university websites and in online student magazines. A further limitation of this study is the self-report measures employed to measure empathy. Research has however shown that significant associations exist between students' self-reported empathy (JSE-S) and simulated patients' evaluations of students' empathy (13). Furthermore, there might have been a recollection bias in play in relation to students' motivations for enrolling in medical education, in particular for third and sixth-year students.

\section{Conclusion}

Overall, our study results, showing high and stable empathy scores across years of curriculum of medical students in Denmark, add to the mixed picture that a large body of cross-sectional studies have conveyed. Longitudinal designs, albeit proven difficult to establish worldwide, are therefore still needed to gain a deeper insight in how empathy levels develop over time in the medical education in Denmark and elsewhere. There were no statistically significant differences in empathy between universities, first, thirdand sixth-year medical students, age groups, parental status or motivations. Our findings are consistent with statistically significant associations found in international studies between empathy scores (measured by JSE-S), female sex and human-oriented specialty preferences. Although specialty preferences are likely to change during a medical education, they may be used meaningfully as predictors of individual student empathy levels.

\section{Abbreviations}

JSE-S - The Jefferson Scale of Empathy - Student Version

\section{Declarations}

\section{Acknowledgements}

Many thanks to our colleagues involved in collecting the data and to the medical students for taking their time to respond to the questionnaire.

\section{Funding}

Funding was received from [The Independent Research Fund Denmark], Grant number: [8108-00021B]. The funding body was not involved in the design of the study. 
The datasets generated and/or analyzed during the current study are available from the corresponding author on reasonable request.

\section{Authors' contributions}

EAH, CMA and SW contributed to the study's conception and design and drafted the manuscript. JS and $\mathrm{NCH}$ contributed to the study's conception and design, revised the publication and gave final approval of the version to be published.

\section{Ethics approval and consent to participate}

The study was conducted in accordance with the principles of the Declaration of Helsinki (41). The study was approved by the university's research ethics committee (REC) [Journal no. 20/5351].

All participants received written information on the study before participation and participation is voluntary. All participants could withdraw from the study at any time with no consequences to their future studies. All data was kept confidential and published anonymously. Complying with European data protection rules, the University of Southern Denmark approved the data processing activities regarding this project and registered the project [Journal no. 10.181].

\section{Consent for publication}

Not applicable

\section{Competing interests}

The authors declare that they have no competing interests.

\section{References}

1. Hojat M. Empathy in Health Professions Education and Patient Care: Springer; 2016.

2. Hojat M, Gonnella JS. Eleven Years of Data on the Jefferson Scale of Empathy-Medical Student Version (JSE-S): Proxy Norm Data and Tentative Cutoff Scores. MEDICAL PRINCIPLES AND PRACTICE. 2015;24(4):344-50.

3. Derksen F, Bensing J, Lagro-Janssen A. Effectiveness of empathy in general practice: a systematic review. Br J Gen Pract. 2013;63(606).

4. Mercer SW, Reynolds WJ. Empathy and quality of care. Br J Gen Pract. 2002;52 Suppl:S9-12.

5. Epstein RM, Hadee T, Carroll J, Meldrum SC, Lardner J, Shields CG. "Could this be something serious?" Reassurance, uncertainty, and empathy in response to patients' expressions of worry. Journal of general internal medicine. 2007;22(12):1731-9.

6. Hellstrom 0 . Dialogue medicine: A health-liberating attitude in general practice. Patient education and counseling. 1998;35(3):221-31. 
7. Neumann M, Edelhäuser F, Kreps G, Scheffer C, Lutz G, Tauschel D, et al. Can patient-provider interaction increase the effectiveness of medical treatment or even substitute it? An exploration on why and how to study the specific effect of the provider. Patient education and counseling. 2010;80:307-14.

8. Undeland M, Malterud K. Diagnostic interaction: the patient as a source of knowledge? Scandinavian journal of primary health care. 2008;26(4):222-7.

9. Quince T, Thiemann P, Benson J, Hyde S. Undergraduate medical students' empathy: current perspectives. Adv Med Educ Pract. 2016;7:443-55.

10. Derksen F, Bensing J, Kuiper S, van Meerendonk M, Lagro-Janssen A. Empathy: what does it mean for GPs? A qualitative study. Fam Pract. 2015;32(1):94-100.

11. Hojat M, Gonnella JS, Mangione S, Nasca TJ, Veloski JJ, Erdmann JB, et al. Empathy in medical students as related to academic performance, clinical competence and gender. Medical education. 2002;36(6):522-7.

12. Hojat M, Bianco JA, Mann D, Massello D, Calabrese LH. Overlap between empathy, teamwork and integrative approach to patient care. Medical teacher. 2014:1-4.

13. Berg K, Majdan JF, Berg D, Veloski J, Hojat M. A comparison of medical students' self-reported empathy with simulated patients' assessments of the students' empathy. Medical teacher. 2011;33(5):388-91.

14. Andersen FA, Johansen A-SB, Søndergaard J, Andersen CM, Assing Hvidt E. Revisiting the trajectory of medical students' empathy, and impact of gender, specialty preferences and nationality: a systematic review. BMC medical education. 2020;20(1):52.

15. Chopik WJ, O'Brien E, Konrath SH. Differences in Empathic Concern and Perspective Taking Across 63 Countries. Journal of Cross-Cultural Psychology. 2016;48(1):23-38.

16. Oh J, Chopik WJ, Konrath S, Grimm KJ. Longitudinal Changes in Empathy Across the Life Span in Six Samples of Human Development. Social Psychological and Personality Science. 2019;11(2):244-53.

17. Piumatti G, Abbiati M, Baroffio A, Gerbase MW. Associations between motivational factors for studying medicine, learning approaches and empathy among medical school candidates. Advances in Health Sciences Education. 2019;24(2):287-300.

18. Gonçalves-Pereira M, Loureiro J, Trancas B, Papoila A, Caldas-de-Almeida JM. Empathy as Related to Motivations for Medicine in a Sample of First-Year Medical Students. Psychological Reports. 2013;112(1):73-88.

19. Grühn D, Rebucal K, Diehl M, Lumley M, Labouvie-Vief G. Empathy across the adult lifespan: Longitudinal and experience-sampling findings. Emotion. 2008;8(6):753-65.

20. Ramboll Sb. Surveyxact by Ramboll 2021 [Available from: https://www.surveyxact.dk.

21. World Health Organisation. Process of translation and adaptation of instruments 2018 [22 May 2018]. Available from: http://www.who.int/substance_abuse/research_tools/translation/en/. 
22. Garcia AA. Cognitive interviews to test and refine questionnaires. Public health nursing (Boston, Mass). 2011;28(5):444-50.

23. Assing Hvidt E, Søndergaard J, Hvidt NC, Wehberg S, Büssing A, Andersen CM. Development in Danish medical students' empathy: study protocol of a cross-sectional and longitudinal mixedmethods study. BMC medical education. 2020;20(1):54.

24. Hegazi I, Wilson I. Maintaining empathy in medical school: it is possible. Medical teacher. 2013;35(12):1002-8.

25. Quince TA, Kinnersley P, Hales J, da Silva A, Moriarty H, Thiemann P, et al. Empathy among undergraduate medical students: A multi-centre cross-sectional comparison of students beginning and approaching the end of their course. BMC medical education. 2016;16:92.

26. Santos MA, Grosseman S, Morelli TC, Giuliano IC, Erdmann TR. Empathy differences by gender and specialty preference in medical students: a study in Brazil. International journal of medical education. 2016;7:149-53.

27. Tavakol S, Dennick R, Tavakol M. Empathy in UK medical students: differences by gender, medical year and specialty interest. Education for primary care: an official publication of the Association of Course Organisers, National Association of GP Tutors, World Organisation of Family Doctors. 2011;22(5):297-303.

28. Riess H. The Science of Empathy. J Patient Exp. 2017;4(2):74-7.

29. Michalec B, Hafferty FW. Challenging the clinically-situated emotion-deficient version of empathy within medicine and medical education research. Soc Theory Health. 2021:1-19.

30. Quince T, Thiemann P, Benson J, Hyde S. Undergraduate medical students' empathy: current perspectives. Adv Med Educ Pract. 2016;7:443-55.

31. Stepien KA, Baernstein A. Educating for empathy. A review. Journal of general internal medicine. 2006;21(5):524-30.

32. Christov-Moore L, Simpson EA, Coudé G, Grigaityte K, lacoboni M, Ferrari PF. Empathy: gender effects in brain and behavior. Neurosci Biobehav Rev. 2014;46 Pt 4(Pt 4):604-27.

33. Halper L, Cowgill C, Rios K. Gender bias in caregiving professions: The role of perceived warmth. Journal of Applied Social Psychology. 2019;49.

34. Sommerlad A, Huntley J, Livingston G, Rankin KP, Fancourt D. Empathy and its associations with age and sociodemographic characteristics in a large UK population sample. PloS one. 2021;16(9):e0257557.

35. Hojat M, Gonnella JS, Nasca TJ, Mangione S, Vergare M, Magee M. Physician empathy: definition, components, measurement, and relationship to gender and specialty. Am J Psychiatry. 2002;159(9):1563-9.

36. Chen D, Lew R, Hershman W, Orlander J. A Cross-sectional Measurement of Medical Student Empathy. Journal of general internal medicine. 2007;22(10):1434-8. 
37. Weisz E, Zaki J. Motivated empathy: a social neuroscience perspective. Curr Opin Psychol. 2018;24:67-71.

38. Lockwood PL, Ang Y-S, Husain M, Crockett MJ. Individual differences in empathy are associated with apathy-motivation. Scientific Reports. 2017;7(1):17293.

39. Nair CS, Adams P, Mertova P. Student Engagement: The Key to Improving Survey Response Rates. Quality in Higher Education. 2008;14(3):225-32.

40. Steinmetz C, Thompson S, Marshall N. Surveying international university students: The case of the $5 \%$ response rate. Issues in Educational Research. 2020;30(3).

41. World Medical Association Declaration of Helsinki. Ethical principles for medical research involving human subjects. Jama. 2013;310(20):2191-4.

\section{Tables}


Table 1

Baseline characteristics of participants $(N=672)$ and all medical students in the target population $(N=$ 4178). The $\mathrm{p}$-values refer to a Chi-squared test between respondents and non-respondents, excluding potential missing values.

\begin{tabular}{|c|c|c|c|}
\hline Variable & Participants & Target population & Response rates and p-values \\
\hline & $\mathbf{N}(\%)$ & $\mathbf{N}(\%)$ & \\
\hline All & $672(100.0)$ & $4178(100.0)$ & $16.1 \%$ \\
\hline University & & & $p<0.001$ \\
\hline AAU & $64(9.5)$ & $406(9.7)$ & $15.8 \%$ \\
\hline $\mathrm{AU}$ & $213(31.7)$ & $1306(31.3)$ & $16.3 \%$ \\
\hline KU & $164(24.4)$ & $1552(37.1)$ & $10.6 \%$ \\
\hline SDU & $231(34.4)$ & $914(21.9)$ & $25.3 \%$ \\
\hline Sex & & & $p<0.001$ \\
\hline Male & $165(24.6)$ & $1407(33.7)$ & $11.7 \%$ \\
\hline Female & $507(75.4)$ & $2771(66.3)$ & $18.3 \%$ \\
\hline Age categories & & & $p=0.3046$ \\
\hline $18-24$ years old & $434(64.6)$ & $2610(62.5)$ & $16.6 \%$ \\
\hline $25+$ & $238(35.4)$ & $1544(37.0)$ & $15.4 \%$ \\
\hline Educational year & & & $p=0.1763$ \\
\hline $1 \mathrm{st}$ & $280(41.7)$ & $1624(38.9)$ & $17.2 \%$ \\
\hline $3 r d$ & $212(31.5)$ & $1326(31.7)$ & $16.0 \%$ \\
\hline 6th & $180(26.8)$ & $1228(29.4)$ & $14.7 \%$ \\
\hline \multicolumn{4}{|l|}{ Living situation } \\
\hline Alone & $177(26.3)$ & & \\
\hline With spouse/partner & $238(35.4)$ & & \\
\hline With others & $257(38.2)$ & & \\
\hline \multicolumn{4}{|c|}{ Parental status: children } \\
\hline Yes & $32(4.8)$ & & \\
\hline No & $640(95.2)$ & & \\
\hline \multicolumn{4}{|l|}{ Specialty preference } \\
\hline General practice & $111(16.5)$ & & \\
\hline
\end{tabular}




\begin{tabular}{|c|c|c|}
\hline Variable & Participants Target population & Response rates and p-values \\
\hline Anesthesiology & $46(6.8)$ & \\
\hline $\begin{array}{l}\text { Dermatology and } \\
\text { venerology }\end{array}$ & $8(1.2)$ & \\
\hline Endocrinology & $13(1.9)$ & \\
\hline Gynecology/obstetrics & $52(7.7)$ & \\
\hline Infection medicine & $10(1.5)$ & \\
\hline Cardiology & $14(2.1)$ & \\
\hline Surgery & $46(6.8)$ & \\
\hline Neurosurgery & $14(2.1)$ & \\
\hline Neurology & $19(2.8)$ & \\
\hline Oncology & $8(1.2)$ & \\
\hline Ortopedic surgery & $23(3.4)$ & \\
\hline Psychiatry & $23(3.4)$ & \\
\hline Pediatrics & $64(9.5)$ & \\
\hline Thoracic surgery, cardiac surgery & $9(1.3)$ & \\
\hline Less frequent category, $\mathrm{N}<10$ & $67(10.0)$ & \\
\hline Missing & $145(21.6)$ & \\
\hline
\end{tabular}


Table 2

Motivations for studying medicine (categorized) by explanatory factors. Percentages are row-wise. It was possible to state more than one motivation: $\mathrm{N}=253$ participants stated one motivational factor, $\mathrm{N}=301$ two, $\mathrm{N}=50$ three, $\mathrm{N}=2$ four and $\mathrm{N}=66$ none.

\begin{tabular}{|c|c|c|c|c|c|c|}
\hline \multicolumn{7}{|c|}{ Motivations for studying medicine } \\
\hline Variable & $\begin{array}{l}\mathrm{N} \\
(100 \%)\end{array}$ & Biology & Prestige & $\begin{array}{l}\text { Helping } \\
\text { others }\end{array}$ & $\begin{array}{l}\text { Personal } \\
\text { experiences }\end{array}$ & None \\
\hline Overall & 672 & $\begin{array}{l}412 \\
(61.3)\end{array}$ & $\begin{array}{l}90 \\
(13.4)\end{array}$ & $411(61.2)$ & $100(14.9)$ & $\begin{array}{l}66 \\
(9.8)\end{array}$ \\
\hline \multicolumn{7}{|l|}{ University } \\
\hline AAU & 64 & $\begin{array}{l}37 \\
(57.8)\end{array}$ & $5(7.8)$ & $48(75.0)$ & $11(17.2)$ & $2(3.1)$ \\
\hline $\mathrm{AU}$ & 213 & $\begin{array}{l}144 \\
(67.6)\end{array}$ & $\begin{array}{l}29 \\
(13.6)\end{array}$ & $132(62.0)$ & $31(14.6)$ & $\begin{array}{l}21 \\
(9.9)\end{array}$ \\
\hline $\mathrm{KU}$ & 164 & $\begin{array}{l}98 \\
(59.8)\end{array}$ & $\begin{array}{l}27 \\
(16.5)\end{array}$ & $97(59.1)$ & $16(9.8)$ & $\begin{array}{l}15 \\
(9.1)\end{array}$ \\
\hline SDU & 231 & $\begin{array}{l}133 \\
(57.6)\end{array}$ & $\begin{array}{l}29 \\
(12.6)\end{array}$ & $134(58.0)$ & $42(18.2)$ & $\begin{array}{l}28 \\
(12.1)\end{array}$ \\
\hline \multicolumn{7}{|l|}{ Sex } \\
\hline Male & 165 & $\begin{array}{l}93 \\
(56.4)\end{array}$ & $\begin{array}{l}29 \\
(17.6)\end{array}$ & $99(60.0)$ & $15(9.1)$ & $\begin{array}{l}18 \\
(10.9)\end{array}$ \\
\hline Female & 507 & $\begin{array}{l}319 \\
(62.9)\end{array}$ & $\begin{array}{l}61 \\
(12.0)\end{array}$ & $312(61.5)$ & $85(16.8)$ & $\begin{array}{l}48 \\
(9.5)\end{array}$ \\
\hline \multicolumn{7}{|l|}{ Age category } \\
\hline $18-24$ years old & 434 & $\begin{array}{l}273 \\
(62.9)\end{array}$ & $\begin{array}{l}54 \\
(12.4)\end{array}$ & $264(60.8)$ & $63(14.5)$ & $\begin{array}{l}44 \\
(10.1)\end{array}$ \\
\hline $25+$ & 238 & $\begin{array}{l}139 \\
(58.4)\end{array}$ & $\begin{array}{l}36 \\
(15.1)\end{array}$ & $147(61.8)$ & $37(15.5)$ & $\begin{array}{l}22 \\
(9.2)\end{array}$ \\
\hline \multicolumn{7}{|l|}{ Educational year } \\
\hline $1 \mathrm{st}$ & 280 & $\begin{array}{l}162 \\
(57.9)\end{array}$ & $\begin{array}{l}38 \\
(13.6)\end{array}$ & $158(56.4)$ & $54(19.3)$ & $\begin{array}{l}34 \\
(12.1)\end{array}$ \\
\hline $3 r d$ & 212 & $\begin{array}{l}141 \\
(66.5)\end{array}$ & $\begin{array}{l}23 \\
(10.8)\end{array}$ & $135(63.7)$ & $32(15.1)$ & $\begin{array}{l}15 \\
(7.1)\end{array}$ \\
\hline 6th & 180 & $\begin{array}{l}109 \\
(60.6)\end{array}$ & $\begin{array}{l}29 \\
(16.1)\end{array}$ & $118(65.6)$ & $14(7.8)$ & $\begin{array}{l}17 \\
(9.4)\end{array}$ \\
\hline \multicolumn{7}{|l|}{ Living situation } \\
\hline Alone & 177 & $\begin{array}{l}94 \\
(53.1)\end{array}$ & $\begin{array}{l}18 \\
(10.2)\end{array}$ & $96(54.2)$ & $32(18.1)$ & $\begin{array}{l}21 \\
(11.9)\end{array}$ \\
\hline
\end{tabular}




\begin{tabular}{|lclllll|}
\hline \multicolumn{7}{|c|}{ Motivations for studying medicine } \\
\hline With spouse/partner & 238 & $\begin{array}{l}149 \\
(62.6)\end{array}$ & $\begin{array}{l}28 \\
(11.8)\end{array}$ & $151(63.4)$ & $35(14.7)$ & 23 \\
\hline With others & 257 & $\begin{array}{l}169 \\
(65.8)\end{array}$ & $\begin{array}{l}44 \\
(17.1)\end{array}$ & $164(63.8)$ & $33(12.8)$ & 22 \\
\hline $\begin{array}{l}\text { Parental status: } \\
\text { children }\end{array}$ & & & & & & $(8.6)$ \\
\hline Yes & 32 & $\begin{array}{l}18 \\
(56.3)\end{array}$ & $4(12.5)$ & $16(50.0)$ & $8(25.0)$ & $3(9.4)$ \\
\hline No & 640 & $\begin{array}{l}394 \\
(61.6)\end{array}$ & $\begin{array}{l}86 \\
(13.4)\end{array}$ & $395(61.7)$ & $92(14.4)$ & 63 \\
\hline
\end{tabular}


Table 3

Distribution of JSE-S empathy scores: mean and standard deviation (SD), median and interquartile range (IQR), and range (minimum-maximum)

\begin{tabular}{|c|c|c|c|c|}
\hline Variable & $\mathbf{N}$ & Mean (SD) & Median (IQR) & Range \\
\hline All & 672 & $112.7(10.8)$ & $113.0(106.7-120.0)$ & 51.0 to 139.0 \\
\hline \multicolumn{5}{|l|}{ University } \\
\hline AAU & 64 & $112.8(10.0)$ & $113.0(106.5-119.0)$ & 91.0 to 134.0 \\
\hline$A U$ & 213 & $113.2(10.0)$ & $114.0(107.0-120.0)$ & 82.0 to 136.0 \\
\hline KU & 164 & $112.6(11.8)$ & $113.0(106.2-121.0)$ & 51.0 to 139.0 \\
\hline SDU & 231 & $112.3(10.9)$ & $112.0(106.0-120.0)$ & 66.0 to 134.0 \\
\hline \multicolumn{5}{|l|}{ Sex } \\
\hline Male & 165 & $110.0(10.7)$ & $111.0(104.0-117.0)$ & 66.0 to 131.0 \\
\hline Female & 507 & $113.6(10.6)$ & $114.0(107.0-121.0)$ & 51.0 to 139.0 \\
\hline \multicolumn{5}{|l|}{ Age categories } \\
\hline 18-24 years old & 434 & $112.5(10.4)$ & $113.0(107.0-120.0)$ & 66.0 to 136.0 \\
\hline $25+$ & 238 & $113.1(11.4)$ & $114.0(106.0-121.0)$ & 51.0 to 139.0 \\
\hline \multicolumn{5}{|l|}{ Educational year } \\
\hline $1 \mathrm{st}$ & 280 & $112.3(11.6)$ & $113.0(106.0-120.0)$ & 51.0 to 136.0 \\
\hline $3 r d$ & 212 & $113.0(9.5)$ & $113.0(108.0-119.0)$ & 79.0 to 134.0 \\
\hline 6th & 180 & $113.1(10.8)$ & $113.3(106.0-121.0)$ & 82.0 to 139.0 \\
\hline \multicolumn{5}{|l|}{ Living situation } \\
\hline Alone & 177 & $111.4(11.7)$ & $112.0(106.0-118.0)$ & 51.0 to 134.0 \\
\hline With spouse/partner & 238 & $114.2(10.2)$ & $114.0(107.0-122.0)$ & 82.0 to 139.0 \\
\hline With others & 257 & $112.2(10.5)$ & $112.0(107.0-119.0)$ & 66.0 to 136.0 \\
\hline \multicolumn{5}{|c|}{ Parental status: children } \\
\hline Yes & 32 & $113.7(11.2)$ & $112.0(108.0-121.5)$ & 90.0 to 134.0 \\
\hline No & 640 & $112.7(10.8)$ & $113.0(106.2-120.0)$ & 51.0 to 139.0 \\
\hline \multicolumn{5}{|l|}{ Specialty preference } \\
\hline General practice & 111 & $115.5(8.8)$ & $116.0(110.0-121.0)$ & 91.0 to 134.0 \\
\hline Anesthesiology & 46 & $110.6(10.0)$ & $110.5(105.0-117.0)$ & 82.0 to 134.0 \\
\hline
\end{tabular}




\begin{tabular}{|c|c|c|c|c|}
\hline Variable & $\mathbf{N}$ & Mean (SD) & Median (IQR) & Range \\
\hline $\begin{array}{l}\text { Dermatology and } \\
\text { venerology }\end{array}$ & 8 & $112.1(7.7)$ & $110.5(108.0-118.5)$ & 100.0 to 123.0 \\
\hline Endocrinology & 13 & $113.3(13.2)$ & $112.0(106.0-125.0)$ & 84.0 to 130.0 \\
\hline Gynecology/obstetrics & 52 & $114.6(11.5)$ & $115.5(106.0-124.0)$ & 93.0 to 136.0 \\
\hline Infection medicine & 10 & $112.9(8.8)$ & $112.5(110.0-121.0)$ & 96.0 to 127.0 \\
\hline Cardiology & 14 & $109.4(14.5)$ & $111.5(98.0-120.0)$ & 82.0 to 132.0 \\
\hline Surgery & 46 & $108.7(10.1)$ & $111.0(102.0-116.0)$ & 83.0 to 126.0 \\
\hline Neurosurgery & 14 & $108.3(17.7)$ & $115.0(105.0-118.0)$ & 51.0 to 120.0 \\
\hline Neurology & 19 & $112.3(9.5)$ & $113.0(104.0-117.0)$ & 95.0 to 128.0 \\
\hline Oncology & 8 & $112.6(10.9)$ & $113.0(108.5-116.5)$ & 93.0 to 132.0 \\
\hline Ortopedic surgery & 23 & $109.9(13.5)$ & $113.0(105.0-118.0)$ & 66.0 to 128.0 \\
\hline Psychiatry & 23 & $119.7(9.5)$ & $122.0(114.0-127.0)$ & 97.0 to 131.0 \\
\hline Pediatrics & 64 & $116.6(8.8)$ & $118.0(109.5-123.0)$ & 98.0 to 139.0 \\
\hline $\begin{array}{l}\text { Thoracic surgery, } \\
\text { cardiac surgery }\end{array}$ & 9 & $103.7(11.7)$ & $109.0(93.0-114.0)$ & 88.0 to 117.0 \\
\hline Less frequent category, $\mathrm{N}<10$ & 67 & $111.0(11.5)$ & $109.0(104.0-119.0)$ & 66.0 to 133.0 \\
\hline Missing & 145 & $111.6(10.1)$ & $112.0(105.3-118.0)$ & 79.0 to 133.0 \\
\hline \multicolumn{5}{|l|}{ Motivations } \\
\hline Biology (no) & 217 & $113.2(12.1)$ & $114.0(107.0-122.0)$ & 51.0 to 139.0 \\
\hline Biology (yes) & 412 & $112.9(10.0)$ & $113.0(107.0-120.0)$ & 66.0 to 136.0 \\
\hline Biology (missing) & 43 & $109.0(10.1)$ & $108.0(103.0-118.0)$ & 82.0 to 131.0 \\
\hline Prestige (no) & 539 & $113.1(10.9)$ & $114.0(107.0-121.0)$ & 51.0 to 139.0 \\
\hline Prestige (yes) & 90 & $112.0(10.2)$ & $112.0(106.0-119.0)$ & 88.0 to 134.0 \\
\hline Prestige (missing) & 43 & $109.0(10.1)$ & $108.0(103.0-118.0)$ & 82.0 to 131.0 \\
\hline Helping others (no) & 218 & $112.9(11.5)$ & $114.0(107.0-121.0)$ & 66.0 to 134.0 \\
\hline Helping others (yes) & 411 & $113.0(10.4)$ & $113.0(107.0-120.0)$ & 51.0 to 139.0 \\
\hline Helping others (missing) & 43 & $109.0(10.1)$ & $108.0(103.0-118.0)$ & 82.0 to 131.0 \\
\hline Personal experiences (no) & 529 & $112.6(10.8)$ & $113.0(107.0-120.0)$ & 51.0 to 139.0 \\
\hline
\end{tabular}




\begin{tabular}{|lllll|}
\hline Variable & N & Mean (SD) & Median (IQR) & Range \\
\hline Personal experiences (yes) & 100 & $114.7(10.6)$ & $116.0(110.0-122.0)$ & 66.0 to 132.0 \\
\hline Personal experiences (missing) & 43 & $109.0(10.1)$ & $108.0(103.0-118.0)$ & 82.0 to 131.0 \\
\hline At least one motivation stated & 606 & $113.1(10.7)$ & $113.3(107.0-120.0)$ & 51.0 to 139.0 \\
\hline None stated & 66 & $109.4(11.3)$ & $110.0(103.0-118.0)$ & 79.0 to 134.0 \\
\hline
\end{tabular}


Table 4

Estimated regression coefficients and corresponding $95 \%$ confidence intervals in parentheses from both univariable and multivariable linear regression models $(N=672)$. Overall Wald-test $p$-values for categories with more than two levels are in italics.

\begin{tabular}{|c|c|c|c|c|}
\hline & Univariable model & & Multivariable model & \\
\hline Variable & Estimate (95\% Cl) & p-value & Estimate (95\% Cl) & p-value \\
\hline \multicolumn{5}{|l|}{ Motivations } \\
\hline Biology (yes) & $0.4(-1.3 ; 2.1)$ & 0.6348 & $0.0(-1.9 ; 2.0)$ & 0.9788 \\
\hline Prestige (yes) & $-0.8(-3.2 ; 1.6)$ & 0.5027 & $-0.6(-3.0 ; 1.9)$ & 0.6429 \\
\hline Helping others (yes) & $0.8(-0.9 ; 2.4)$ & 0.3731 & $-0.5(-2.5 ; 1.5)$ & 0.6224 \\
\hline Personal experiences (yes) & $2.3(0.0 ; 4.6)$ & 0.0459 & $2.1(-0.5 ; 4.8)$ & 0.1094 \\
\hline None stated & $-3.6(-6.4 ;-0.9)$ & 0.0092 & $-4.1(-7.6 ;-0.5)$ & 0.0267 \\
\hline University & & 0.8444 & & 0.9552 \\
\hline AAU & Ref & & Ref & \\
\hline$A U$ & $0.4(-2.6 ; 3.4)$ & 0.8079 & $0.6(-2.4 ; 3.7)$ & 0.6935 \\
\hline KU & $-0.2(-3.4 ; 2.9)$ & 0.8776 & $0.5(-2.6 ; 3.6)$ & 0.7557 \\
\hline SDU & $-0.5(-3.5 ; 2.5)$ & 0.7249 & $0.1(-2.9 ; 3.1)$ & 0.9446 \\
\hline Female Sex & $3.7(1.8 ; 5.5)$ & $<0.001$ & $2.5(0.6 ; 4.5)$ & 0.0115 \\
\hline \multicolumn{5}{|l|}{ Age categories } \\
\hline 18-24 years old & Ref & & Ref & \\
\hline $25+$ & $0.6(-1.1 ; 2.3)$ & 0.4809 & $0.2(-2.4 ; 2.9)$ & 0.8644 \\
\hline Educational year & & 0.6359 & & 0.7725 \\
\hline $1 \mathrm{st}$ & Ref & & Ref & \\
\hline $3 r d$ & $0.8(-1.2 ; 2.7)$ & 0.4325 & $0.7(-1.3 ; 2.6)$ & 0.4898 \\
\hline 6th & $0.8(-1.2 ; 2.9)$ & 0.4167 & $0.1(-2.9 ; 3.2)$ & 0.9265 \\
\hline Living situation & & 0.0195 & & 0.2596 \\
\hline Alone & Ref & & Ref & \\
\hline With spouse/partner & $2.8(0.7 ; 4.9)$ & 0.0081 & $1.8(-0.4 ; 4.0)$ & 0.1095 \\
\hline With others & $0.8(-1.2 ; 2.9)$ & 0.4287 & $0.6(-1.5 ; 2.8)$ & 0.5698 \\
\hline
\end{tabular}




\begin{tabular}{|c|c|c|c|c|}
\hline & Univariable model & & Multivariable model & \\
\hline Yes & Ref & & Ref & \\
\hline No & $-1.0(-4.8 ; 2.8)$ & 0.6039 & $0.8(-3.1 ; 4.8)$ & 0.6820 \\
\hline Specialty preference & & $<0.001$ & & $<0.001$ \\
\hline General practice & Ref & & Ref & \\
\hline Anesthesiology & $-4.9(-8.5 ;-1.3)$ & 0.0083 & $-3.4(-7.1 ; 0.3)$ & 0.0737 \\
\hline $\begin{array}{l}\text { Dermatology and } \\
\text { venerology }\end{array}$ & $-3.4(-10.9 ; 4.2)$ & 0.3800 & $-4.1(-11.6 ; 3.4)$ & 0.2833 \\
\hline Endocrinology & $-2.2(-8.3 ; 3.8)$ & 0.4651 & $-1.3(-7.4 ; 4.8)$ & 0.6703 \\
\hline Gynecology/obstetrics & $-0.9(-4.3 ; 2.6)$ & 0.6185 & $-1.5(-5.0 ; 2.0)$ & 0.3954 \\
\hline Infection medicine & $-2.6(-9.4 ; 4.2)$ & 0.4533 & $-2.3(-9.1 ; 4.6)$ & 0.5164 \\
\hline Cardiology & $-6.1(-11.9 ;-0.2)$ & 0.0415 & $-4.7(-10.6 ; 1.2)$ & 0.1174 \\
\hline Surgery & $-6.8(-10.4 ;-3.1)$ & $<0.001$ & $-6.3(-10.0 ;-2.7)$ & $<0.001$ \\
\hline Neurosurgery & $-7.2(-13.0 ;-1.3)$ & 0.0162 & $-7.4(-13.3 ;-1.5)$ & 0.0142 \\
\hline Neurology & $-3.2(-8.3 ; 1.9)$ & 0.2221 & $-2.7(-7.8 ; 2.5)$ & 0.3080 \\
\hline Oncology & $-2.9(-10.4 ; 4.7)$ & 0.4545 & $-3.0(-10.6 ; 4.6)$ & 0.4372 \\
\hline Ortopedic surgery & $-5.6(-10.3 ;-0.9)$ & 0.0204 & $-4.4(-9.2 ; 0.3)$ & 0.0676 \\
\hline Psychiatry & $4.2(-0.5 ; 8.9)$ & 0.0791 & $5.4(0.6 ; 10.2)$ & 0.0268 \\
\hline Pediatrics & $1.1(-2.1 ; 4.4)$ & 0.4875 & $1.6(-1.7 ; 4.9)$ & 0.3503 \\
\hline $\begin{array}{l}\text { Thoracic surgery, } \\
\text { cardiac surgery }\end{array}$ & $-11.8(-19.0 ;-4.7)$ & 0.0012 & $-11.3(-18.5 ;-4.1)$ & 0.0022 \\
\hline Less frequent category, $\mathrm{N}<10$ & $-4.5(-7.7 ;-1.3)$ & 0.0056 & $-3.7(-6.9 ;-0.4)$ & 0.0261 \\
\hline Missing & $-3.9(-6.5 ;-1.3)$ & 0.0032 & $-3.3(-6.0 ;-0.6)$ & 0.0157 \\
\hline Constant & & & $111.2(105.4 ; 117.1)$ & $<0.001$ \\
\hline
\end{tabular}

\section{Figures}




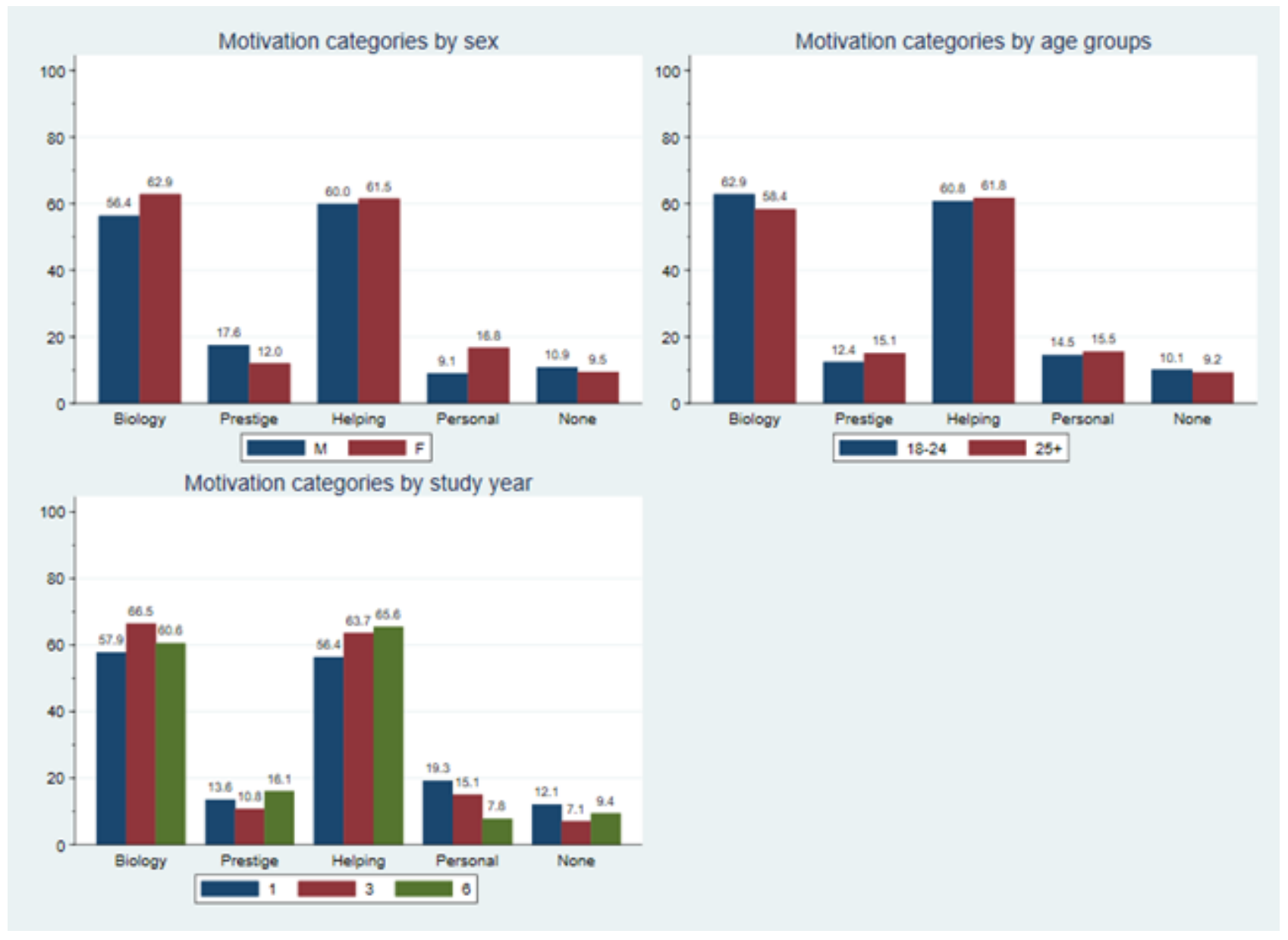

\section{Figure 1}

Motivations for studying medicine (categorized) by sex, age groups and educational (study) year.

\section{Supplementary Files}

This is a list of supplementary files associated with this preprint. Click to download.

- SupplementaryTableS1.docx 